\title{
Ж.С. Макашева
}

Казахский университет международных отношений и мировых языков

имени Абылай хана, Казахстан, г. Алматы

e-mail: makasheva5585@bk.ru

\section{СПЕЦИФИКА СТРАТЕГИЧЕСКИХ ПРИОРИТЕТОВ РАЗВИТИЯ ЦЕНТРААЬНОАЗИАТСКОГО РЕГИОНА}

\begin{abstract}
Главным признаком современного мирохозяйственного развития является глобальная взаимозависимость, которая охватывает и видоизменяет политические, экономические, социальные и экологические условия. Актуальность исследования обусловлена недостаточным исследованием процессов трансформации мировой экономики и участия в ней стран Центральноазиатского региона (ЦАР). В связи с этим, цель статьи - проанализировать процесс трансформации мировой экономики в условиях институциональной глобализации, институциональное обеспечение международного экономического взаимодействия, сотрудничество в рамках международных финансовых институтов, которые являются неотъемлемой составляющей развития мировой экономики; обосновать стратегические приоритеты развития ЦАР. Ведущим методом к исследованию Аанной проблемы является метод анализа, позволяющий комплексно рассмотреть стратегические приоритеты развития ЦАР в условиях глобализации. В статье преАставлена система использования Авойных стандартов в сферах международного регулирования, выявлены препятствия Аля реализации преимуществ свободной торговли, раскрыты факторы институционального преобразования международных экономических отношений. Материалы статьи представляют практическую ценность А^я Аальнейшего изучения перспективы международной конкурентоспособности ЦАР, которая способна развиваться на собственной интемектуальной основе с продуцированием новейших научно-технологических решений в инновационных сегментах мирового рынка и обеспечивать наллежащие условия жизнедеятельности нации.
\end{abstract}

Ключевые слова: экономика, международные отношения, глобализация, развитие, мировая политика.

\author{
Zh.S. Makasheva \\ Kazakh Ablai Khan University of International Relations and \\ World Languages, Kazakhstan, Almaty \\ e-mail: makasheva5585@bk.ru \\ Specifics of strategic development priorities \\ of the Central Asian region
}

The main feature of modern world economic development is global interdependence, which embraces and modifies political, economic, social and environmental conditions. The relevance of the study is due to insufficient research on the processes of transformation of the world economy and the participation in it of the countries of the Central Asian region (CAR). In this regard, the goal of the paper is to analyze the process of transformation of the world economy in the context of institutional globalization, institutional support of international economic interaction, cooperation within the framework of international financial institutions, which are an integral component of the development of the world economy; substantiate strategic priorities for the development of the CARs. The leading method to the study of this issue is the analysis method, which allows to comprehensively consider the strategic priorities of the development of the countries of the Central Asian region in the context of globalization. The paper presents the system of using double standards in the areas of international regulation, identifies obstacles to realizing the benefits of free trade, and reveals the factors of institutional transformation of international economic relations. The materials of the paper are of practical value for the further studying the prospects for the international competitiveness of the countries of the Central Asian region, which is able to develop on its own intellectual basis with the production of the latest scientific and technological solutions in the innovative segments of the world market and provide the proper conditions for the life of the nation.

Key words: economy, international relations, globalization, development, world politics. 


\author{
Ж.С. Мақашева \\ Абылай хан атындағы Қазақ халықаралық қатынастар және \\ әлем тілдері университеті, Қазақстан, Алматы к. \\ e-mail: makasheva5585@bk.ru \\ Орталық Азия аймағын дамытудың \\ стратегиямық басымдықтарының ерекшелігі
}

\begin{abstract}
Қазіргі әлемдік экономикалық, дамудың басты ерекшелігі - саяси, экономикалық, әлеуметтік және экологиялық жағдайларды қамтитын және өзгертетін жаһандық өзара тәуелділік. Зерттеудің өзектілігі әлемдік экономикада болып жатқан трансформация үрдісі барысында Орталық, Азия аймағы елдерінің рөлі мен орнын анықтау. Осыған байланысты мақаланың мақсаты институционалды жаһандану, халықаралық экономикалық өзара іс-қимылды институционалдық қолдау, әлемдік экономика дамуының ажырамас бөлігі болып табылатын халықаралық қаржы институттары аясындағы ынтымақтастық жағдайында әлемдік экономиканың өзгеру процесін талдау; Орталық Азияның Аамуы барысындағы стратегиялық басымдықтарын негіздеу. Бұл мәселені зерттеудің жетекші әдісі - жаһандану жағдайында Орталық Азияның дамуының стратегиялық басымдықтарын жан-жақты қарастыруға мүмкіндік беретін та^дау әдісі. Мақалада еркін сауданың артықшылықтарын жүзеге асырудағы кедергілер анықталған, халықаралық экономикалық қатынастардағы институциона^ды өзгерістердің факторлары көрсетілген. Мақала материалдары Орталық, Азияның халықаралық, бәсекеге қабілеттілік перспективаларын әрі қарай зерттеу үшін практикалық маңызы бар. Орталық Азияның халықаралық бәсекеге қабілеттілігі өзінің интемлектуалды негізінде әлемдік нарықтың инновациялық сегменттеріндегі ең жаңа ғылыми және технологиялық шешімдерді шығарумен дами алады және ұлттың өмір сүруіне тиісті жағдайларды қамтамасыз етуге мүмкіндігі бар.
\end{abstract}

Түйін сөздер: экономика, халықаралық қатынастар, жаһандану, даму, әлемдік саясат.

\section{Введение}

Глобализация способствует общему экономическому прогрессу через распространение инноваций в сфере технологий и менеджмента, активный обмен товарами, услугами, инвестициями. Одновременно усиливаются неравномерность, асинхронность и диспропорциональность развития научно-технологических, производственных, торговых, финансово-инвестиционных отношений как в функциональном, так и в межстрановом аспектах. На одном полюсе современной мировой экономики концентрируются страны - глобальные лидеры, ключевыми детерминантами успеха которых в третьем тысячелетии становятся интеллектуализация, социализация, экологизация производства и среды жизнедеятельности. На другом полюсе мировой экономики - большинство стран, для которых экономическая глобализация проявляется, прежде всего, как качественно новые условия развития, на которые практически невозможно влиять, но обязательно надо учитывать. Страны, которые не успеют за динамикой новой эпохи, не только не получат дивидендов от глобализации, но и могут стать ее заложниками, оказаться на обочине глобальных, общецивилизационных процессов. Очевидной становится интернационализация хозяйственной жизни, взаимопроникновение разных видов деятель- ности: научно-технической, инвестиционной, финансово-коммерческой и др., что приводит к институциональным изменениям. Поэтому актуальными являются исследования процессов трансформации мировой экономики и участие в ней стран Центральноазиатского региона.

Исследованию вопросов международных интеграционных процессов в мировой экономике, институциональных преобразований, проблем мировых рынков товаров, капитала в условиях финансовой глобализации и либерализации инвестиционных режимов посвящены работы известных отечественных и зарубежных ученых. Несмотря на многочисленные научные исследования различных аспектов включения государств в процессы международного экономического взаимодействия, современные реалии обусловливают необходимость развития научной мысли по вопросам трансформации мирохозяйственных процессов, развития институциональной составляющей экономического сотрудничества (Саямов Ю.Н., 2018; Kang W., Ratti R.A. \& Vespignani J., 2020; Mertzanis C., Garas S. \& Abdel-Maksoud A., 2020).

\section{Обоснование выбора темы, цели и задачи}

Осипов и другие в своем исследовании отмечают, что экономическая ситуация в России, санкционная война, невнятная позиция 
российского государства привели к смене вектора экономического развития, а также к трансформации экономики. Авторы в своей работе рассматривают институциональные условия для формирования территорий опережающего развития. В данном исследовании проанализированы статистические данные по регионам Дальневосточного федерального округа, где началось строительство таких территорий. Авторы оценивают рентабельность инвестиций территории опережающего развития и предлагают механизмы реализации промышленной политики. Важно отметить, что авторы считают, что стратегическое планирование должно основываться на институциональной матрице и вариантах ее развития (Osipov V.S., Skryl T.V. \& Evseev V.O., 2016). В другом исследовании также рассматриваются актуальные вопросы импортозамещения с учетом потенциала малого и среднего предпринимательства в нефтегазодобывающих регионах Севера в условиях кризиса и санкций. Проанализирована деятельность малых и средних предприятий и обоснована необходимость замещения импортных товаров отечественными в Ханты-Мансийском автономном округе. В исследовании устанавливаются стратегические приоритеты государственной поддержки, направленной на импортозамещение малых и средних предприятий. Авторы дают оценку экономического развития предпринимательства в традиционных отраслях коренных малочисленных народов Севера как одного из перспективных способов импортозамещения (Bogomolova L.L., 2016).

В современных условиях хозяйствования ЦАР должна шире использовать такие формы международного сотрудничества государств, как зона свободной торговли, единое таможенное и экономическое пространство, а также сотрудничество в инвестиционной сфере (Feny F. \& Badalova E.V., 2019:137). Цель статьи - проанализировать процесс трансформации мировой экономики в условиях институциональной глобализации, институциональное обеспечение международного экономического взаимодействия, сотрудничество в рамках международных финансовых институтов, которые являются неотъемлемой составляющей развития мировой экономики; обосновать стратегические приоритеты развития ЦАР в условиях глобализации, с учетом ключевых мирохозяйственных тенденций и потенциала экономики.

\section{Научная методология исследования}

В процессе исследования были использованы базовые методы научного познания, а также методы синтеза и анализа информации. Был также использован сравнительный метод исследования. Был проведен теоретический анализ научной литературы.

Метод синтеза применяется для сбора целого из его функциональных частей. Объединение метода анализа с методом синтеза позволяет получить представления о связях между составляющими объекта изучения. Метод синтеза был использован чтобы упорядочить информацию о системе свободной торговли, а также с помощью метода анализа раскрыты факторы институционального преобразования международных экономических отношений. Также с помощью соединения методов синтеза и анализа было исследовано понятия глобализации. С помощью сравнительного метода был проанализирован зарубежный опут, а именно, опыт Соединённых Штатов Америки. Позже опыт США был сравнен с опытом ЦАР.

Были также разработаны стратегические приоритеты развития ЦАР. Основными приоритетами являются: системная интеграция в мировое хозяйство с обеспечением реальной международной конкурентоспособности, эффективная международная специализация, скоординированная с внутренней структурной модернизацией и ориентированная на доступные прогрессирующие сегменты мирового рынка, направленная на ликвидацию монопольной зависимости от отдельных зарубежных рынков международная диверсификация, становление собственных транснациональных экономических структур с глобальным менеджментом, интеграционное взаимодействие со странами мира; взвешенная политика региональной интеграции с приоритетом органичного вхождения, непосредственное участие в формировании мировой институциональной инфраструктуры через взаимодействие с МВФ, Всемирным банком, системой Генерального соглашения по тарифам и торговле/Всемирной торговой организацией (ГАТТ/ВТО), специализированными правительственными и неправительственными организациями в области связи и информационного обмена, транспорта, энергетики, труда, торговле и развитию, промышленного развития, сельского хозяйства и продовольствия, эффективное взаимодействие с мировыми регулятивными организациями должно базироваться на 
предварительных комплексных оценках возможных положительных результатов и негативных последствий, определении национальных экономических приоритетов и обеспечении национальной экономической безопасности, обеспечение надлежащего уровня экономической безопасности с действенными механизмами защиты от неблагоприятных изменений международной конъюнктуры и финансовых кризисов. Было определено, что эффективная реализация определенных приоритетов ЦАР возможна только средствами адекватной экономической политики с производительным использованием собственных, прежде всего интеллектуальных, ресурсов.

Проведен теоретический анализ научной литературы по тематике исследования. В частности, были рассмотрены работы авторов, в которых они проводили анализ статистических данных по регионам Дальневосточного федерального округа. Также была рассмотрена работа, в которой проанализирована деятельность малых и средних предприятий и обоснована необходимость замещения импортных товаров отечественными в Ханты-Мансийском автономном округе.

\section{Результаты и обсуждение}

\section{Глобализачия как структурированный пройесc}

Институциональные преобразования международных экономических отношений определялись многими факторами, важнейшие среди которых: перестройка социально-экономической структуры, массовая приватизация, создание финансовой инфраструктуры, возникновение и развитие финансовых рынков, либерализация внешнеэкономических связей. В течение последних десятилетий глобализация проявлялась и исследовалась как ключевая тенденция мирохозяйственного развития. Современные системные трансформации придают ей новое качество - глобализация из тенденции перерастает в самодостаточный, определенным образом структурированный процесс.

Уже сегодня можно говорить и о глобальной институционализации экономики, когда на равноправные и даже более значительные роли, чем традиционные субъекты международных экономических отношений (государства), претендуют не только транснациональные корпорации (ТНК), региональные межгосударственные интеграционные объединения с совокупными триллионными ВВП, международные организации (Международный валютный фонд, Всемирный банк, Всемирная торговая организация, Международная организация труда), но и города - мировые финансово-информационные центры, практически экстерриториальны и функционально автономны (Нью-Йорк, Лондон, Франкфуртна-Майне, Париж и др.) с ежедневными многомиллиардными объемами валютных операций, отдельные индивиды - научные работники, университетские профессора, творческие личности, бизнесмены. В недрах Интернета зародилась не только «виртуальная экономика», а и «виртуальная политика», «виртуальная дипломатия» и тому подобное. Глобально организованные мультимедиа-компании влияют непосредственно на ум людей средствами несилового и неэкономического характера (Бурьянов С.А., 2019:22; Filippova O.A. \& Filippov Z.S., 2020). Проявления глобализации такого рода развивают традиционные рамки экономического анализа, побуждают к нетривиальным обобщениям. При этом важно понимать, что даже унаследованных глобальных проблем развития человеческой цивилизации (загрязнение окружающей среды, истощение жизненно важных природных ресурсов, бедность и растущий разрыв между странами в качестве жизни) новые субъекты решить не могут, как это не смогли сделать транснациональные корпорации.

Глобальные процессы обостряют конкурентную борьбу, приводят к изменениям в перераспределении финансовых и инвестиционных ресурсов, что часто происходит не в пользу стран с низким и средним уровнем развития, предопределяя их маргинализацию в мировом хозяйстве. В этих условиях важным средством конкурентной борьбы в современном мире, а также формой защиты собственных экономик от неблагоприятных перепадов мирохозяйственной конъюнктуры является фрагментация мировой экономики за счет формирования группировок и блоков государств, которые проводят скоординированную экономическую политику. Это является вынужденным шагом и ответом на усиление глобальной конкуренции. В то же время с глобализационными процессами каждое государство осуществляет собственную политику по защите национальных интересов.

Экономическая агрессия глобальных рынков подталкивает страны к проведению национально ориентированной инвестиционной стратегии по укреплению собственных рынков - стратегии наиболее быстро растущих стран, таких как Ки- 
тай, Индия, Бразилия, Южная Корея. Делая ставку на развитие внутренних рынков и привлекая иностранные инвестиции, они неуклонно сокращают отставание от стран «золотого миллиарда» по показателю доходов на душу населения. Для стран с менее развитыми рыночными экономиками в новой глобальной системе остаются значительные препятствия для реализации национальных преимуществ свободной торговли и повышения инвестиционной привлекательности экономики. Кроме этого, либерализация инвестиционного рынка в соответствии с требованиями Соглашения по торговым аспектам инвестиционных мер (ТРИМС) несет ряд весомых угроз национальной экономической безопасности.

Функционирование международных институтов является условием и неотъемлемой составляющей развития мировой экономики. После последнего финансового кризиса, который в полной мере продемонстрировал разрушительный потенциал и механизмы передачи негативных воздействий глобального характера, в новом свете выглядят проблемы функционирования международных финансовых организаций (Щитов А.Н., 2019:76). Дело даже не в том, что страны, соблюдая программы реформирования по универсальным рецептам Международного валютного фонда (МВФ), редко достигают ощутимых экономических успехов, а страны, ориентированные на собственную промышленную и научно-технологическую политику (которая по очевидным причинам остается вне поля зрения МВФ), такого успеха, как правило, достигают. Важно, что приходит понимание беспрецедентно непродуктивного и даже вредного для становления новых эффективных экономик использования огромных финансовых ресурсов, которые аккумулируются в международных финансовых организациях. Среди основных внутренних ограничений государств, относительно включения в мирохозяйственные процессы, является несовершенство институционального обеспечения международного экономического взаимодействия (Дятлов С.А. \& Губа М.Н., 2020:16).

Стратегические приоритеты развития мировой экономики в условиях глобализации

Несмотря на задекларированное равноправие развитых и менее развитых стран, в отношении доступа к рынкам и ресурсам, практика свидетельствует о неравенстве условий функционирования разных стран в рамках Всемирной торговой организации (ВТО). Интенсификация либерализации международной торговли в конце $\mathrm{XX}$ в. не создала равных условий для разных государств. Для стран с менее развитыми рыночными экономиками в новой глобальной торговой системе остаются значительные препятствия для реализации преимуществ свободной торговли, что, прежде всего, определяется их институциональной недоразвитостью, отсутствием должного финансового и кадрового обеспечения (Taranov P., Sobin I. \& Leimoev A., 2019:18). При этом фактически сохраняется значительная асимметрия в реальных (а не формально задекларированных) возможностях доступа на зарубежные рынки товаров и услуг. Эта асимметрия усиливается в условиях уменьшения роли относительно простых (тарифных) методов регулирования и относительного повышения значения более сложных и часто скрытых форм нетарифного протекционизма. Последние очень широко применяются развитыми странами в форме:

- различного рода стандартов, технических правил, санитарных и фитосанитарных требований, в том числе международных, в формировании которых превалирующая роль принадлежит наиболее развитым странам;

- использование антидемпинговых механизмов на основе несовершенных методик определения случаев демпинга, которые создают простор для произвольных решений;

- ограничительной деловой практики ТНК, которые даже в формально либерализованной торговой системе имеют возможности не допускать нежелательных для них участников на наиболее динамичные рынки в современных секторах экономики, не говоря уже о формировании замкнутых систем внутрикорпоративного оборота товаров и услуг;

- использование скрытых механизмов политического содействия собственным компаниям со стороны правительств наиболее развитых стран и продвижения их товаров и услуг на наиболее перспективные внешние рынки.

Развивающиеся страны предъявляют свой счет системе использования двойных стандартов в трех сферах международного регулирования, которые тесно связаны между собой: тарифы, субсидии и инвестиции. Асимметричность экономических результатов такого регулирования подтверждается, в частности, такими данными. Ежегодно ЦАР выделяет на поддержку сельского хозяйства 500 млн евро, что составляет около $40 \%$ общего бюджета ЦАР (хотя стоит отметить о дискуссиях о целесообразности и честности распределения средств на поддержку аграриев. В частности, как выяснилось, львиную долю средств на поддержку сельского хозяйства полу- 
чают гигантские продовольственные концерны, а не мелкие фермеры) (Малевич Ю.И., 2018:86).

Соединенные Штаты Америки субсидируют фермеров, выращивающих хлопок, на сумму около 3 млрд долл. ежегодно. Эти денежные вливания влияют на мировую цену хлопка, опуская ее на $25 \%$, или до уровня, который не покрывает расходы на выращивание хлопка в Индии. Значительная часть невостребованной рынком продукции западных производителей, попадая в развивающиеся страны, подрывает местное производство. Поставкам же конкурирующей продукции из этих стран на западные рынки препятствуют протекционистские тарифы. Также, если средние тарифы на импорт европейской продукции в США составляют всего $2 \%$ от ее стоимости, то аналогичные на импорт в США из некоторых стран, что развиваются, - в 20 раз выше (Морозов М.К., 2018:73).

На современном этапе экономического развития ЦАР значительно ограничен методологический инструментарий государства по повышению институциональной конкурентоспособности. В частности, несмотря на то, что ЦАР является членом ВТО, условия, на которых привлекаются иностранные инвестиции, значительно снижают их эффективность для некоторых отечественных субъектов хозяйствования (Сурма И.В., 2018:5). Следовательно, только эффективная государственная стратегия интеграции в глобальную экономическую среду позволит ЦАР воспользоваться всеми преимуществами этого процесса и избежать значительных угроз национальной экономической безопасности. Конкурентоспособной может быть национальная экономика, которая эффективно использует возможности глобализации. Стратегическими приоритетами развития ЦАР в условиях глобализации, с учетом ключевых мирохозяйственных тенденций и потенциала экономики, должны стать:

- системная интеграция в мировое хозяйство с обеспечением реальной международной конкурентоспособности;

- эффективная международная специализация, скоординированная с внутренней структурной модернизацией и ориентированная на доступные прогрессирующие сегменты мирового рынка;

- направленная на ликвидацию монопольной зависимости от отдельных зарубежных рынков международная диверсификация;

- становление собственных транснациональных экономических структур с глобальным ме- неджментом (ресурсно-технологических, агропромышленных; технико-технологических, приборостроения, аэрокосмической техники, самолетостроения, судостроения; транспортно-инфраструктурных - нефть, газ, электроэнергетическая);

- интеграционное взаимодействие со странами мира; взвешенная политика региональной интеграции с приоритетом органичного вхождения;

- непосредственное участие в формировании мировой институциональной инфраструктуры через взаимодействие с МВФ, Всемирным банком, системой Генерального соглашения по тарифам и торговле/Всемирной торговой организацией (ГАТТ/ВТО), специализированными правительственными и неправительственными организациями в области связи и информационного обмена, транспорта, энергетики, труда (Международная организация труда - МОТ), торговле и развитию (Конференция ООН по торговле и развитию - ЮНКТАД), промышленного развития (Организация Объединённых Наций по промышленному развитию - ЮНИДО), сельского хозяйства и продовольствия (Продовольственная и сельскохозяйственная организация $\mathrm{OOH} \mathrm{-} \mathrm{ФАО)} \mathrm{и} \mathrm{др.;}$

- эффективное взаимодействие с мировыми регулятивными организациями должно базироваться на предварительных комплексных оценках возможных положительных результатов и негативных последствий, определении национальных экономических приоритетов и обеспечении национальной экономической безопасности;

- обеспечение надлежащего уровня экономической безопасности с действенными механизмами защиты от неблагоприятных изменений международной конъюнктуры и финансовых кризисов.

Эффективная реализация определенных приоритетов возможна средствами адекватной экономической политики с производительным использованием собственных, прежде всего интеллектуальных, ресурсов. Инновационное развитие как базовую постиндустриальную ценность можно обеспечить только через систему подготовки и поддержки работников нового типа. Инновационная экономика требует инновационного образования и менеджмента (Малова Т.А., 2018:7). Несмотря на значительные потери ресурсов, научно-технологического и кадрового потенциала и времени, ЦАР имеет перспективы определенной международной кон- 
курентоспособности, способна развиваться на собственной интеллектуальной основе с продуцированием новейших научно-технологических решений в инновационных сегментах мирового рынка и обеспечивать надлежащие условия жизнедеятельности нации.

В целом же, доступ той или иной страны к мировым ресурсам (в том числе инвестиционным) - это, прежде всего, возможность участия в распределении мирового ВВП в зависимости от ее статуса в международном разделении труда. Поскольку рассчитывать на изменение схемы международных продаж проблематично, то для отсталых стран остается один выход - делать ставку на развитие собственных сетей создания стоимости. Первый шаг на таком пути - развитие внутреннего рынка, ориентация на национального покупателя с последующим включением на более выгодных условиях в международное разделение труда. А для стран с небольшими рынками выгодной может оказаться направленность на прилегающих региональных лидеров, с получением дополнительных преимуществ от создания формальных и неформальных торговых блоков, в расчете на устойчивые связи и преференции.

\section{Заключение}

Главным признаком современного мирохозяйственного развития является глобальная взаимозависимость, которая охватывает и видоизменяет политические, экономические, социальные и экологические условия. На сегодня успеха достигают структурно сбалансированные национальные экономики - с нормально функционирующими реальным и крепким (здоровым) финансовым секторами экономики, адекватной внутренней и международной социально-экономической структуре соотношением производственного и непроизводственного государственного и частного секторов, эффективными воспроизводственными механизмами в материальной и духовной сферах. Оптимизация именно этих параметров обеспечивает внутренние составляющие конкурентоспособности национальных экономик. В статье представлена система использования двойных стандартов в сферах международного регулирования, выявлены препятствия для реализации преимуществ свободной торговли, раскрыты факторы институционального преобразования международных экономических отношений.

На начальных этапах рыночной трансформации переходных экономик важнейшими ее институциональными предпосылками считались либерализация, приватизация и корпоратизация, макроэкономическая стабилизация. Сегодня доминирует идея способности государства обеспечить среду, которая стимулирует внутреннюю и международную конкурентоспособность национальных предприятий и объединений. Учитывая это, решающее значение для экономического развития ЦАР приобретает макро- и микросбалансированная структурная политика и ее институциональное обеспечение.

Таким образом, в данной работе была достигнута первоначальная цель, а именно, был проанализирован процесс трансформации мировой экономики в условиях институциональной глобализации, институциональное обеспечение международного экономического взаимодействия, сотрудничество в рамках международных финансовых институтов, которые являются неотъемлемой составляющей развития мировой экономики. Также в данной работе обоснованы стратегические приоритеты развития ЦАР в условиях глобализации с учетом ключевых мирохозяйственных тенденций и потенциала экономики.

\section{Литература}

Бурьянов С.А. Глобальная трансформация мирового правопорядка и проблема применения силы в международных отношениях / С.А. Бурьянов // Новеллы права и политики 2018: материалы Международной научно-практической конференции. - 2019. - С. 19-23.

Дятлов С.А. Трансформация системы международных экономических отношений под влиянием цифровой промышленной революции / С.А. Дятлов, М.Н. Губа // Экономика и управление: проблемы, решения. - 2020. - Т. 1. - №1. - С. 11-17.

Малевич Ю.И. Трансформация междисциплинарного подхода к изучению современных международных отношений / Ю.И. Малевич // Исследование международных отношений в Республике Беларусь: состояние и перспективы материалы Республиканской научно-практической конференции, посвященной 25 -летию кафедры международных отношений БГУ. 2018. - С. 84-87.

Малова Т.А. Конкуренция за мировое лидерство как фактор риска глобальной нестабильности / Т.А. Малова // Страховое дело. -2018 . - Т. 6. - №303. - С. 3-9. 
Морозов М.К. Понятие лидерства в международных отношениях и историческая эволюция его содержания / М.К. Морозов // Скиф. Вопросы студенческой науки. - 2018. - Т. 2. - №18. - С. 71-74.

Саямов Ю.Н. Международные отношения и глобальные социальные трансформации / Ю.Н. Саямов // Социально-гуманитарные знания. - 2018. - Т. 4. - С. 219-232.

Сурма И.В. Новые вызовы и угрозы в условиях трансформации международных отношений / И.В Сурма // Современные вызовы и угрозы в условиях трансформации международных отношений. - 2018. - С. 4-5.

Щитов А.Н. Трансформация международных отношений: дипломатия и право / А.Н. Щитов // Актуальные вопросы экономики, управления и права: сборник научных трудов (ежегодник). - 2019. - Т. 2-3. - С. $73-78$.

Bogomolova L.L. Development of government support for import substitution in small and medium enterprises of northern regions / L.L. Bogomolova // Polish Journal of Management Studies. - 2016. Vol. 13. No. 2. P. 18-26.

Feny F. The process of globalization in modern international relations and the problems of democracy transformation / F. Feny, E.V. Badalova // "State and society in modern politics": collection of materials of the VI international scientific-practical conference. - 2019. - P. 130-138.

Filippova, O.A. The role of the state program "economic development and innovation-driven economy" in the development of small and medium enterprises / O.A. Filippova, Z.S. Filippov // Smart Innovation, Systems and Technologies. - 2020. - No. 172. P. 725-730.

Kang, W. Global commodity prices and global stock market volatility shocks: Effects across countries / W. Kang, R.A. Ratti, J. Vespignani // Journal of Asian Economics. - 2020. - Article number 101249.

Mertzanis, C. Integrity of financial information and firms' access to energy in developing countries / C. Mertzanis, S. Garas, A. Abdel-Maksoud // Energy Economics. - 2020. - No. 92. - Article number 105005.

Osipov V.S. An analysis of economic issues of territories of priority development / V.S. Osipov, T.V. Skryl, V.O. Evseev // Research Journal of Applied Sciences. - 2016. - Vol. 11. - No. 9. P. 833-842.

Taranov P. Transformation of the multilateral regulation of international trade relations in an unstable world order / P. Taranov, I. Sobin, A. Leimoev // Economic Security, Account and Right in the Russian Federation: realities and prospects. - 2019. - P. 16-20.

\section{References}

Bogomolova L.L. (2016) Development of government support for import substitution in small and medium enterprises of northern regions. Polish Journal of Management Studies, vol. 13, no 2, pp. 18-26.

Buryanov S.A. (2019) Global'naja transformacija mirovogo pravoporjadka i problema primenenija sily v mezhdunarodnyh otnoshenijah [Global transformation of the world legal order and the problem of the use of force in international relations]. Novelly prava i politiki 2018: materialy Mezhdunarodnoj nauchno-prakticheskoj konferencii, pp. 19-23.

Dyatlov S.A., Guba M.N. (2020) Transformacija sistemy mezhdunarodnyh jekonomicheskih otnoshenij pod vlijaniem cifrovoj promyshlennoj revoljucii [Transformation of the system of international economic relations under the influence of the digital industrial revolution]. Jekonomika i upravlenie: problemy, reshenija, vol. 1, no 1, pp. 11-17.

Feny F., Badalova E.V. (2019) The process of globalization in modern international relations and the problems of democracy transformation. "State and society in modern politics": collection of materials of the VI international scientific-practical conference, pp. $130-138$.

Filippova O.A., Filippov Z.S. (2020) The role of the state program "economic development and innovation-driven economy" in the development of small and medium enterprises. Smart Innovation, Systems and Technologies, no 172, pp. 725-730

Kang W., Ratti R.A., Vespignani J. (2020) Global commodity prices and global stock market volatility shocks: Effects across countries. Journal of Asian Economics, article number 101249.

Malevich Yu.I. (2018) Transformacija mezhdisciplinarnogo podhoda k izucheniju sovremennyh mezhdunarodnyh otnoshenij [Transformation of an interdisciplinary approach to the study of modern international relations]. Issledovanie mezhdunarodnyh otnoshenij v Respublike Belarus': sostojanie i perspektivy materialy Respublikanskoj nauchno-prakticheskoj konferencii, posvjashhennoj 25-letiju kafedry mezhdunarodnyh otnoshenij BGU, pp. 84-87.

Malova T.A. (2018) Konkurencija za mirovoe liderstvo kak faktor riska global'noj nestabil'nosti [Competition for world leadership as a risk factor for global instability]. Strahovoe delo, vol. 6, no 303, pp. 3-9.

Mertzanis C., Garas S., Abdel-Maksoud A. (2020) Integrity of financial information and firms' access to energy in developing countries. Energy Economics, no 92, article number 105005.

Morozov M.K. (2018) Ponjatie liderstva v mezhdunarodnyh otnoshenijah i istoricheskaja jevoljucija ego soderzhanija [The concept of leadership in international relations and the historical evolution of its content]. Skif. Voprosy studencheskoj nauki, vol. 2, no 18 , pp. 71-74.

Osipov V.S., Skryl T.V., Evseev V.O. (2016) An analysis of economic issues of territories of priority development. Research Journal of Applied Sciences, vol. 11, no 9, pp. 833-842.

Sayamov Yu.N. (2018) Mezhdunarodnye otnoshenija i global'nye social'nye transformacii [International relations and global social transformations]. Social'no-gumanitarnye znanija, vol. 4. pp. 219-232.

Shchitov A.N. (2019) Transformacija mezhdunarodnyh otnoshenij: diplomatija i pravo [Transformation of International Relations: Diplomacy and Law]. Aktual'nye voprosy jekonomiki, upravlenija i prava: sbornik nauchnyh trudov (ezhegodnik), vol. 2-3, pp. $73-78$.

Surma I.V. (2018) Novye vyzovy i ugrozy v uslovijah transformacii mezhdunarodnyh otnoshenij [New challenges and threats in the context of the transformation of international relations]. Sovremennye vyzovy i ugrozy v uslovijah transformacii mezhdunarodnyh otnoshenij, pp. 4-5.

Taranov P., Sobin I., Leimoev A. (2019) Transformation of the multilateral regulation of international trade relations in an unstable world order. Economic Security, Account and Right in the Russian Federation: realities and prospects, pp. 16-20. 